\title{
Geostatistical modeling of porosity data in 'oba' field, onshore Niger Delta
}

\author{
Oluseun Adetola Sanuade ${ }^{1 *}$, Akindeji Opeyemi Fajana' ${ }^{1}$, Abayomi Adesola Olaojo², \\ Kehinde David Oyeyemi ${ }^{3}$ and Joel Olayide Amosun ${ }^{1}$ \\ ${ }^{1}$ Department of Geophysics, Federal University Oye-Ekiti, Ekiti State, Nigeria. \\ ${ }^{2}$ Earth Sciences Department, Ajayi Crowther University, Oyo, Nigeria \\ ${ }^{3}$ Department of Industrial Physics, Covenant University, Ota, Ogun State, Nigeria \\ * Corresponding Author: Oluseun Adetola Sanuade Department of Geophysics, Federal University Oye-Ekiti \\ sheunsky@gmail.com +2347038958998
}

\begin{abstract}
A geostatistical approach was used to model porosity of OBA field in onshore area of Niger Delta using simulation technique. The objective is to understand the spatial distribution of porosity and characterize the degree of heterogeneity of underlying formation. Porosity data from twenty-two wells were loaded into SGeMS software. Univariate statistical analysis, experimental semivariogram and Sequential Gaussian Simulation (SGS) were applied on the data. The data was close to normal approximation of Gaussian based of the results of univariate statistics. However, to construct and model horizontal and vertical semivariograms, the data was log-normalized to reduce the coefficient of variation and to get good fit of the model. Parametric semivariogram model shows the range of 72-6480 m, nugget effect of 0.006 and sills of $0.0095,0.0099$ and 0.0111 . Six realizations were generated using SGS algorithm and the results suggest that any one of the realizations can independently represents the true picture of the subsurface geology within the study area. Ranking of realizations shows realization 6 as the best and realization 2 as the lowest. This model could be used as an initial condition for simulation of flow.
\end{abstract}

Key words: geostatistics; stochastic; simulation; porosity; semivariogram 


\section{Introduction}

One of the common problem in earth sciences is the delineation of subsurface properties from sparse and limited number of wells. Such problem was addressed early via contouring which is simple and gives clue about the trend of the variables but the approach is not unique in its result [1]. Later on this problem was addressed through kriging which is robust, and considered powerful in estimation of the weight and value of the regionalized variable on unsampled locations, and the outcome of this estimations is a deterministic model [1]. However, due to the complexity in reservoir properties that vary spatially, and sparseness of information, it is not logical to assign only one value for regionalized variable to construct unique deterministic model of such variable for extremely variable properties. As a result of this situation, stochastic representation of regionalized variable is the best, which follows the concept that any regionalized variable exists as a random variable with specific probability density associated to it $[2,3]$.

Most geological phenomena are extraordinarily complex in their interrelationship and vary widely in geographical extension, and exact description of the geological feature is neither feasible nor economically possible, therefore the results are uncertain in most cases. Such geological feature can be described by stochastic models that give different possible values of realizations with acceptable measurement of error. A simulation method is more sophisticated than a kriging process in that that it allows the user not only to specify statistical anisotropy in terms of semivariogram parameters as kriging does, but also to model heterogeneity by adding a random factor. Honoring spatial distribution and real value of the measured location is corner stone in reducing risk and uncertainty, and therefore stochastic simulation is the best approach to address such cases. With stochastic simulation, the geoscientist is better positioned to evaluate which geological information is relevant [4]. The ability to understand and predict the possible spatial distribution of a property with uncertainty is critical for understanding geological heterogeneity such as grain size, lithology, texture, porosity, permeability, and diagenetic processes. Good prediction of these properties is a sine qua non to proper decision making, planning and management strategy.

Therefore, in this study, conditional sequential Gaussian simulation (SGS), one of the stochastic methods, is used on porosity data to characterize and measure geological feature with uncertainty.

\section{Description and Geology of the study area}

The Niger Delta is situated at the apex of the Gulf of Guinea on the west coast of Africa (Figure 1A). The 'OBA' field is located in the onshore area of Niger-delta as seen in Figure 1B.

The clastic wedge of the Niger Delta occurs along a failed arm of a triple junction systems which was formerly emanated during the breakup that occurred between South American and Africa plates. This process happened in the late Jurassic [6]. Synrift sediments accumulated during the Cretaceous to Tertiary, with the oldest dated sediments of the Albian age. The thickest successions of synrift marine and marginal marine clastics and carbonates were deposited in a series of transgressive and regressive phases [5]. The Niger Delta clastic wedge prograded into the Gulf of Guinea at increased rate that remained steady so as to respond to the evolution of these drainage areas and continuation of basement subsidence. The movement of marine shales of the Akata formation, which are deep-seated, over-pressured and ductile, within the basin, led to the formation of normal faults in the Niger Delta. The Akata shale is believed to have deformed the clastic wedge of the Niger Delta [5]. Majority of those normal faults are syndepositional and produced at the time of progradation of the Delta. The faulting styles produced in the Niger Delta are simple rollover structures with clay filled channel, growth faults, antithetic fault and collapsed crest (Figure 2).

There are three major lithostratigraphic units in the Niger Delta. These are Akata, Agbada and Benin formations (Figure 3). Their depositional environments include marine, deltaic to fluvial environments [8]. 


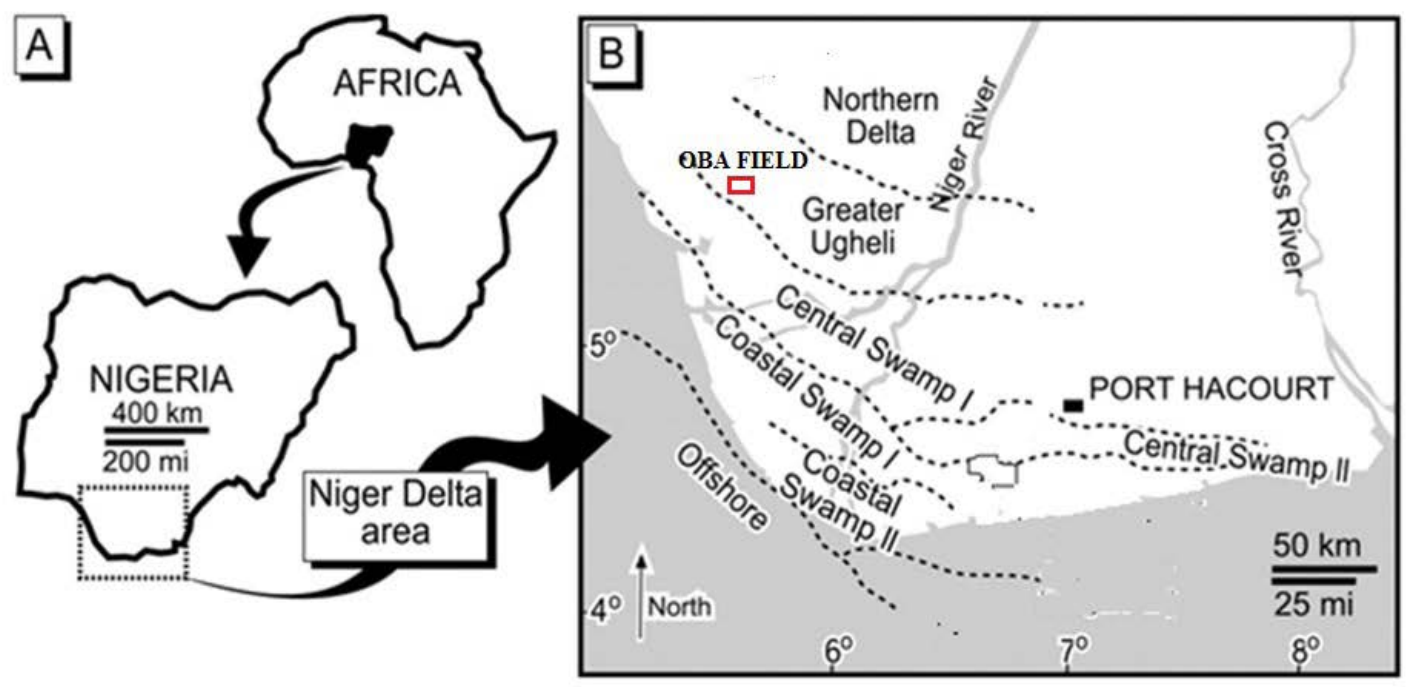

Figure 1: (A) Location of Niger Delta (B) Location of OBA field (modified from [5]).

S

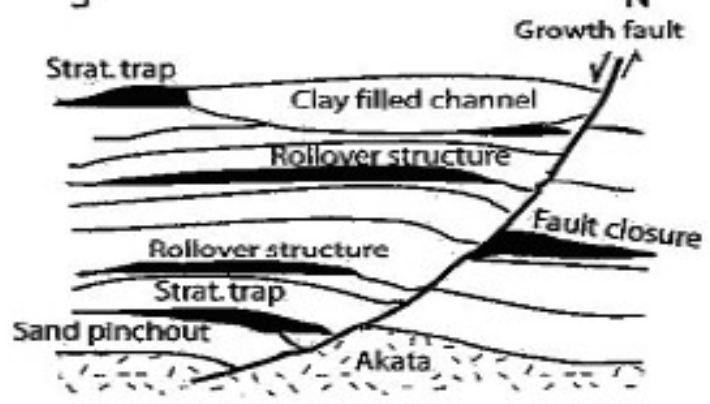

Simple rollover structure with clay filled channel

S

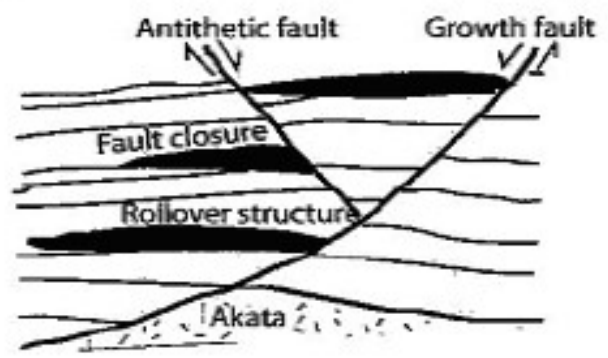

Structure with antithetic fault
S

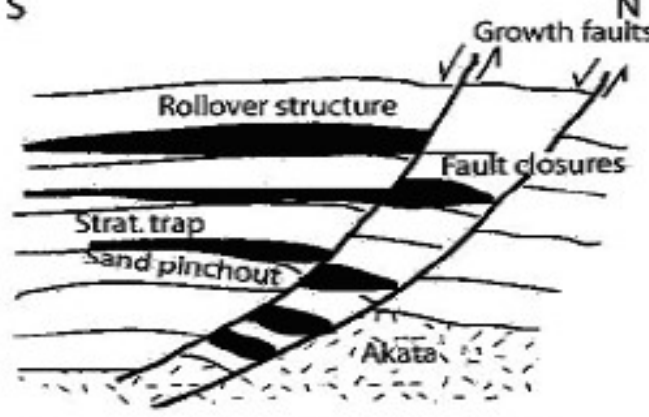

Structure with multiple growth faults

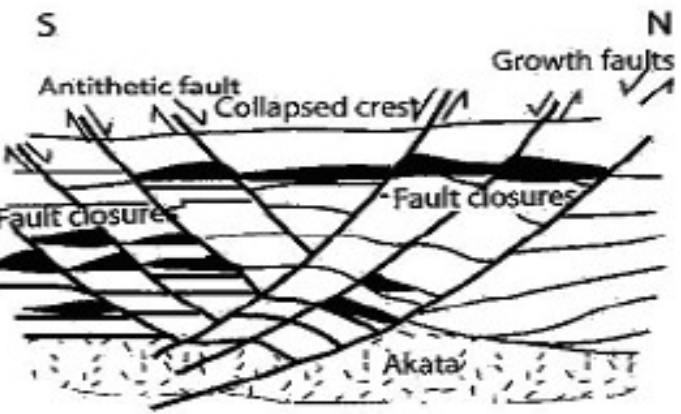

Collapsed crest structure

Figure 2: Niger Delta oil field structures and their associated traps [7].

The thickness of Akata formation is about $6,400 \mathrm{~m}$ at the centre of the clastic wedge. The lithology of the formation are dark gray shales and silts with streaks of sand (having origin tur- bidite flow). The age of this Akata is from Paleocene to Recent. It grades vertically into the overlying Agbada formation [5]. 


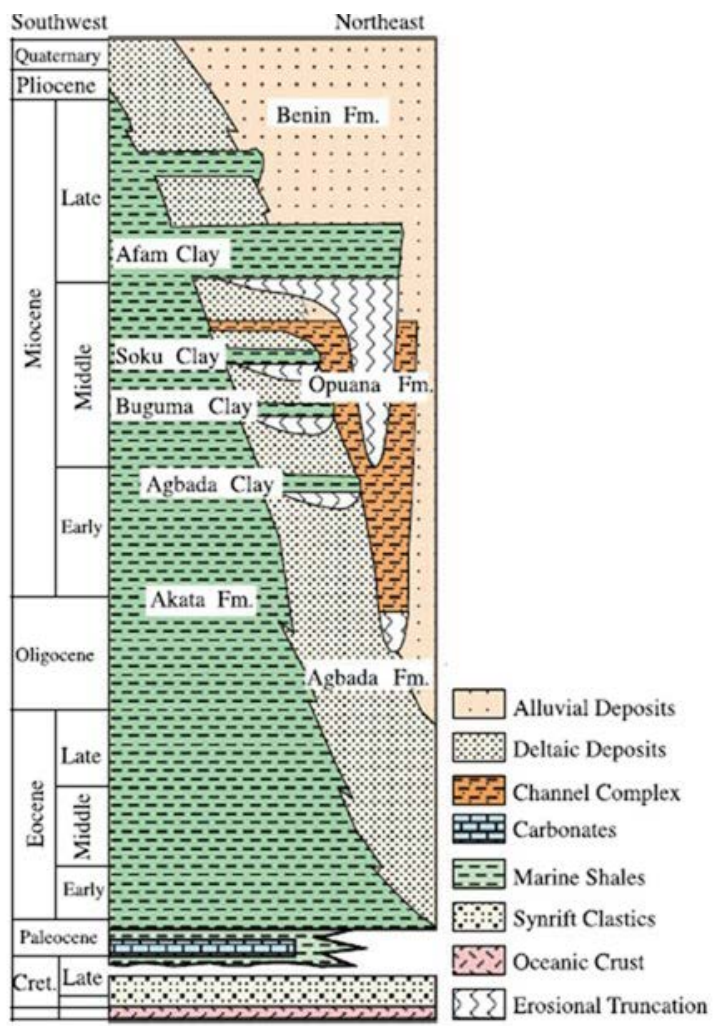

Figure 3: Stratigraphic column showing Formations in the Niger Delta [10].

Agbada Formation is about $3960 \mathrm{~m}$ thick having intercalations of sand and shale. These sands and shales are formed in fluvial-deltaic environment. The age of Agbada Formation ranges from Eocene to Pleistocene.

Benin Formation is on the top of the clastic wedge of Niger Delta. The top of this formation is made up of the recent subaerially-exposed delta top surface. The shallow part of this formation consist of non-marine sands deposited in either upper coastal plain or alluvial depositional environments [5]. The age is from Oligocene to Recent [9].

The main oil reservoir in the Niger Delta is the Agbada Formation [5]. The source rock in the Niger Delta is the marine shale of Akata Formation and/or marine interbedded shale of the Agbada Formation [5, 11]. The primary seal rocks are the interbedded shale of the Agbada Formation. However, the Agbada Formation while suitable for petroleum accumulation, is too deep to be relevant to groundwater storage. There arises therefore the major difference between the region where the petroleum geol- ogist is prospecting for oil, that is, the Agbada Formation, and that, where the hydrogeologist I searching for water - the Benin Formation, in the Niger Delta.

\section{Materials and Methodology}

The data consists of about 2396 porosity measurements from 22 wells distributed in the southwest (SW)-northeast (NE) direction in the area. Sampling was done based on the flow direction of the aquifer in the area. The spacing between the well is irregular (Figure 4). Porosity varies between 0.10 and 0.30 . The porosity data was estimated from sonic logs using equation 1. The depth of the wells varies from 120 to $500 \mathrm{~m}$ and penetrated the Benin Formation

$\varnothing=\frac{\Delta t-\Delta t_{m a}}{\Delta t_{f}-\Delta t_{m a}} \ldots \ldots \ldots$

where: $\varnothing$ is the porosity, $\Delta \mathrm{t}$ is the zone transient time $(\mu \mathrm{s} / \mathrm{ft}), \Delta \mathrm{t}_{\mathrm{f}}$ is the transient time of fluid (189 $\mu \mathrm{s} / \mathrm{ft}$ for water), $\Delta \mathrm{t}_{\mathrm{ma}}$ is the average time of sandstone formation $(52.6 \mu \mathrm{s} / \mathrm{ft})$.

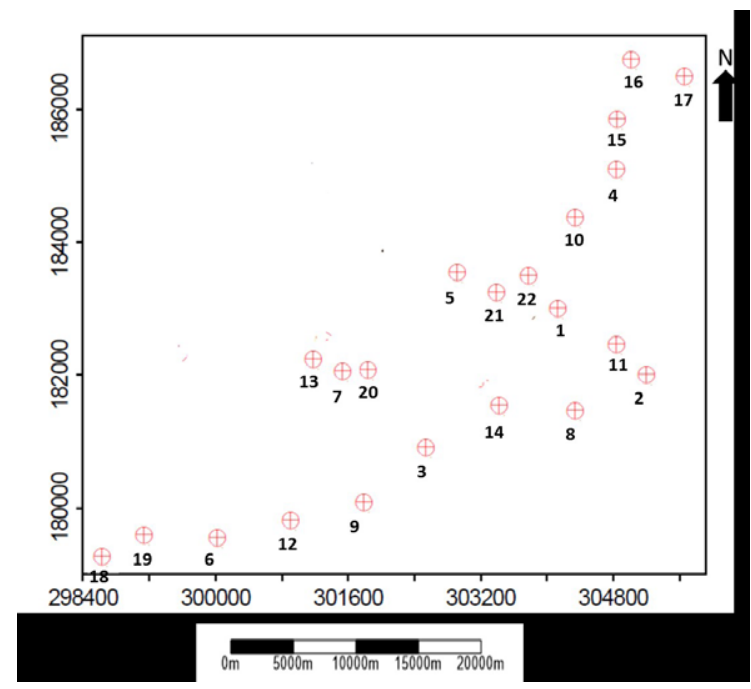

Figure 4: Base map showing well locations.

The data format was changed from excel format to ASCII format and loaded to Minitab 17 well by well to generate various graphical displays of the data [12]. These graphs include histogram, probability density function and cumula- 
tive density function. Minitab 17 software was also used to compute statistics summary and perform normality tests. Golden Surfer 9 was used to develop base map of the wells in the study area.

Descriptive statistics was used to interpret different graph categories and to compare results. Then the data was displayed as box plot to check for possible outliers. Our data was found to be approximately close to Gaussian approximation of normal distribution. Semivariogram plots were generated by calculating variogram at different lags and azimuths using SGeMS software. Then experimental semivariograms were fitted with theoretical model (spherical model). Parameters derived from fitted model were used to identify anisotropy and structural interpretation.

The study area was then gridded, and parameters from semivariogram were used to krige the study area. Afterward the SGS algorithm was applied on the data. This algorithm simulates nodes on a grid in random sequence by first estimating the value at the selected node by kriging with a local neighborhood of conditioning data, and then adding a random component from a normal distribution with zero mean and the kriging standard deviation. After simulation, values are added to the conditioning set for use in simulating additional nodes.

\section{Results and Discussion}

\section{Descriptive Statistics}

The statistical results of the wells show that the porosity distribution ranges from $0.10-0.30$ with a mean of 0.25 . This porosity range is typical of sand/sandstone or shale. However, the mean value indicates that it could represent all the data i.e. normally distributed porosity is equal to the mean or higher than mean. Analysis of quartiles for the porosity indicates that $25 \%$ of the porosity data falls below 0.24 and $75 \%$ falls below 0.30 . The coefficient of variation (CV), standard deviation and variance of the porosity are $0.21,0.06$ and 0.00349 respectively. Coefficients of kurtosis and skewness for the wells are -0.33 and -0.27 respectively. The value of coefficient of kurtosis indicate that the porosity distribution is platykurtic in shape
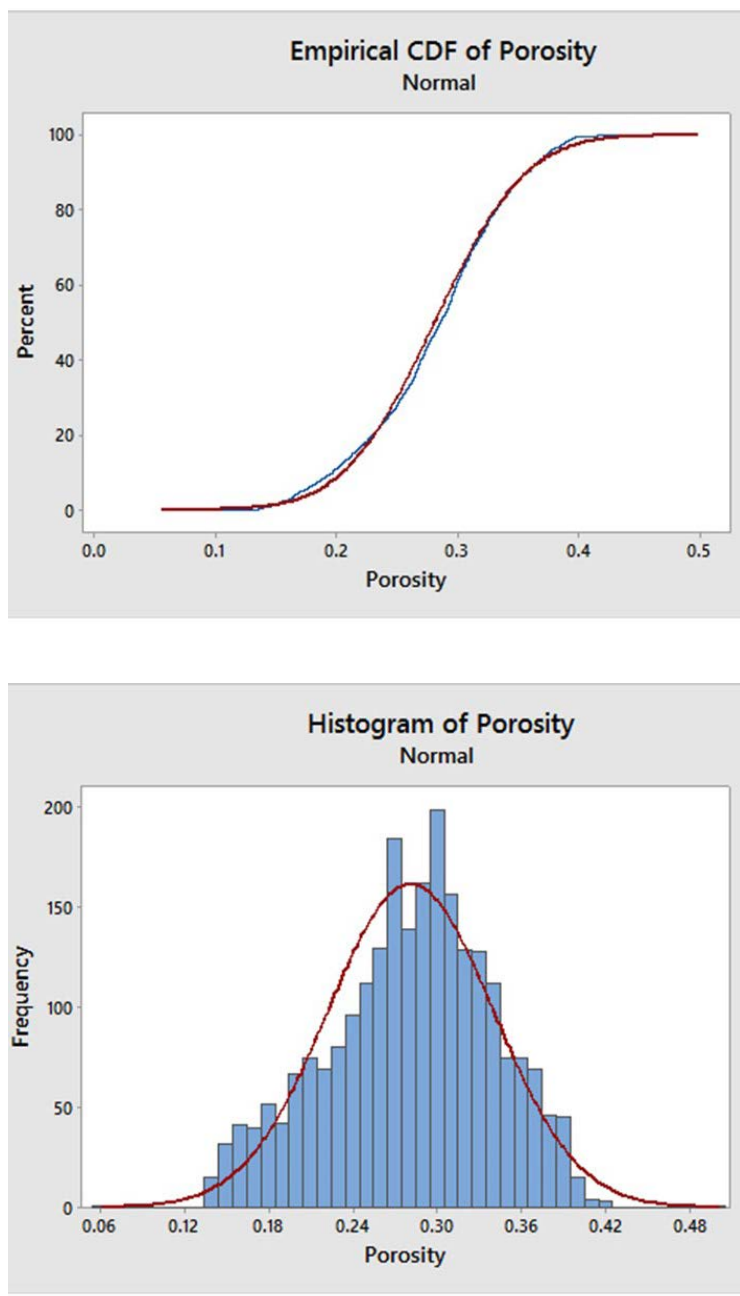

Figure 5a: CDF and PDF of wells in the study area.

having flat top which results from large variations within observations. This means that most of the porosity values are less clustered around the mean with a fairly layout uniform of data. This may indicate local variation in terms of geology which may be as a result of faulting/ fracturing in the area [3].

Figure 5a shows the Cumulative Distribution Function (CDF) and Probability Density Function (PDF) for the wells. The CDF and PDF reveal normally distributed porosity data. Figure $5 \mathrm{~b}$ shows the outliers tests performed on the wells while Figure 5c shows the graphical display of two normality tests for the wells. It was revealed from these tests that the porosity is normally distributed with a very minute outliers. The outlier porosity values were filtered out. 

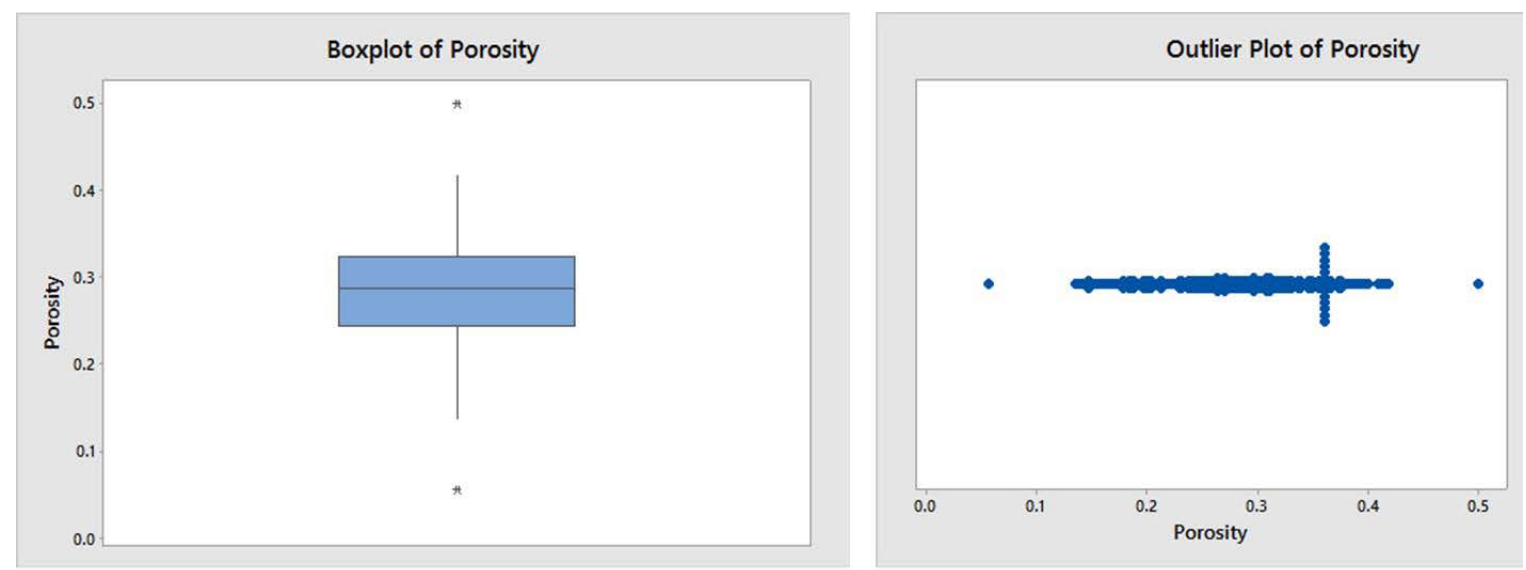

Figure 5b: Outlier tests for the wells.
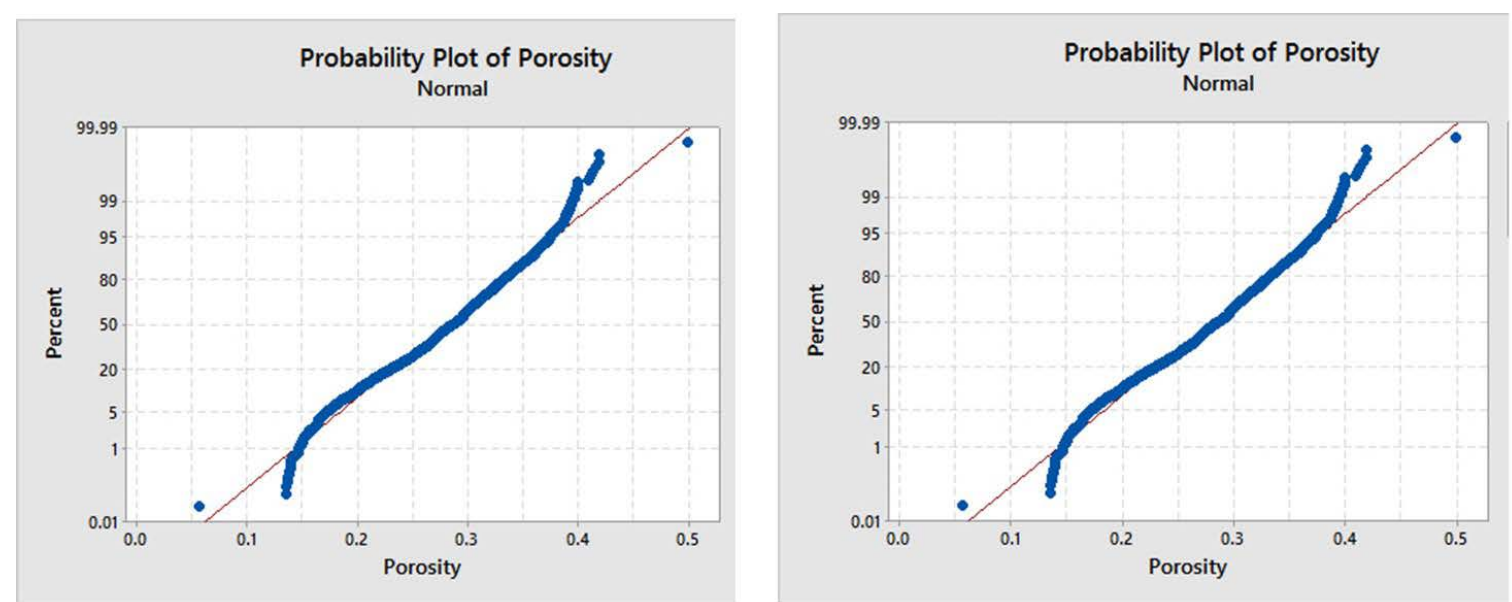

Figure 5c: Anderson-Darling and Kolmogorov-Smirnov normality tests for the wells.

\section{Experimental Semivariogram}

Semivariogram of the data shows structural variability and continuity at major direction azimuth 45 , minor direction azimuth 135 , and vertical direction with range of 6480, 1750 and $72 \mathrm{~m}$ respectively (Figure 6a-c; Table 1). Based on these range of values, the porosity in the study area exhibits anisotropic geometry in all directions. Also, the structural variances (C) of the horizontal direction (0.0039 and 0.0051) are greater than the vertical direction (0.0035). This suggests that porosity in the horizontal direction shows more variability than vertical direction because the space between two points in the horizontal direction (near $500 \mathrm{~m}$ or more) is greater than vertical direction (less than $30 \mathrm{~m}$ ). This might indicate change in facies, intensity in cementation, or secondary porosity that could be caused by fracturing in horizontal direction. The small nugget value shows that there is a small scale variation in the subsurface structure that might be a result of higher degree of cementation or fracture in the subsurface.

The range and nugget effect imply that the length of the spatial autocorrelation is longer than the sampling interval of $72 \mathrm{~m}$ in vertical direction. Therefore, the sampling design is good for this study and it is expected that a good spatial structure will be shown on the interpolated map in further study.

The differences in range suggests the elliptic shape of the semivariogram structure. The sills of parametric semivariogram model are 0.0095 in vertical direction and 0.0099 and 0.0111 in horizontal directions (theoretically 


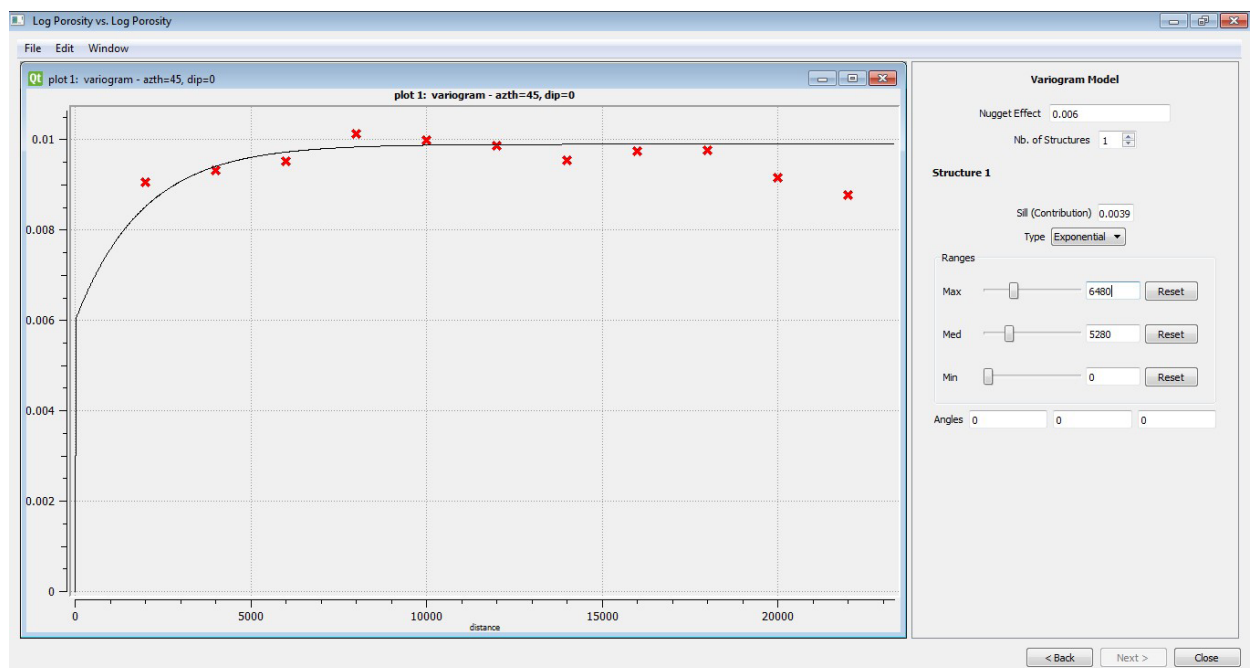

Figure 6a: Experimental and semivariogram model at azimuth 45 (Major direction).

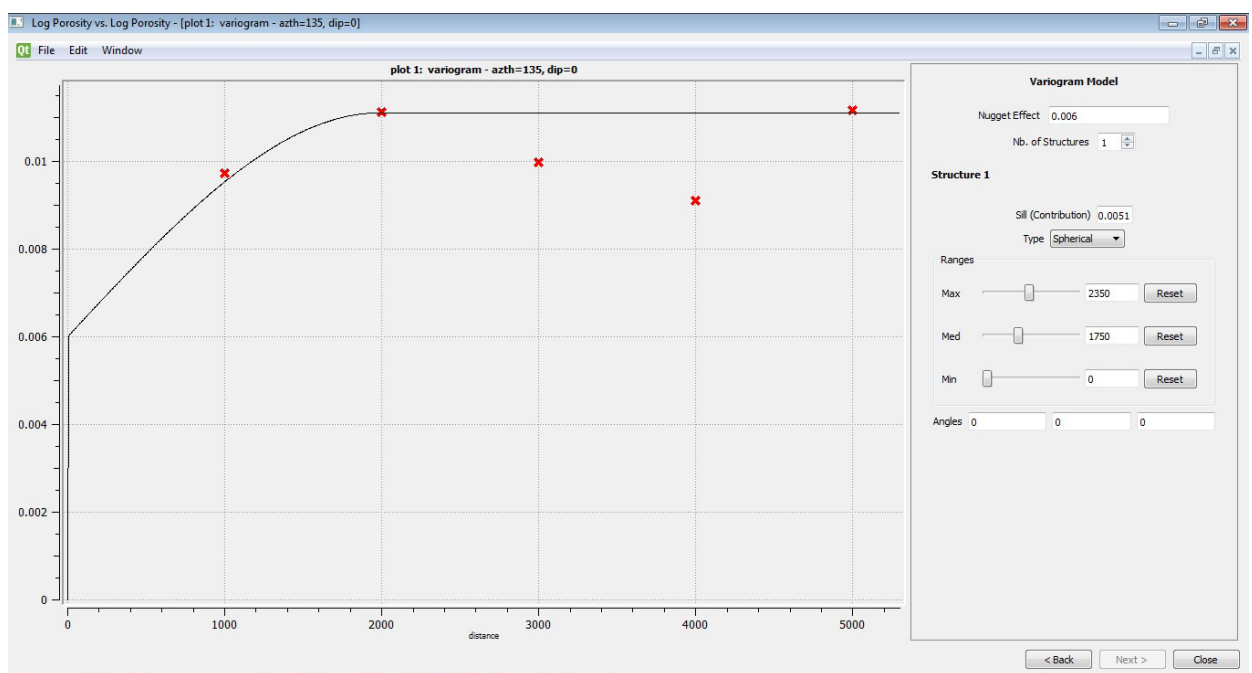

Figure 6b: Experimental and semivariogram model at azimuth 135 (Minor direction).

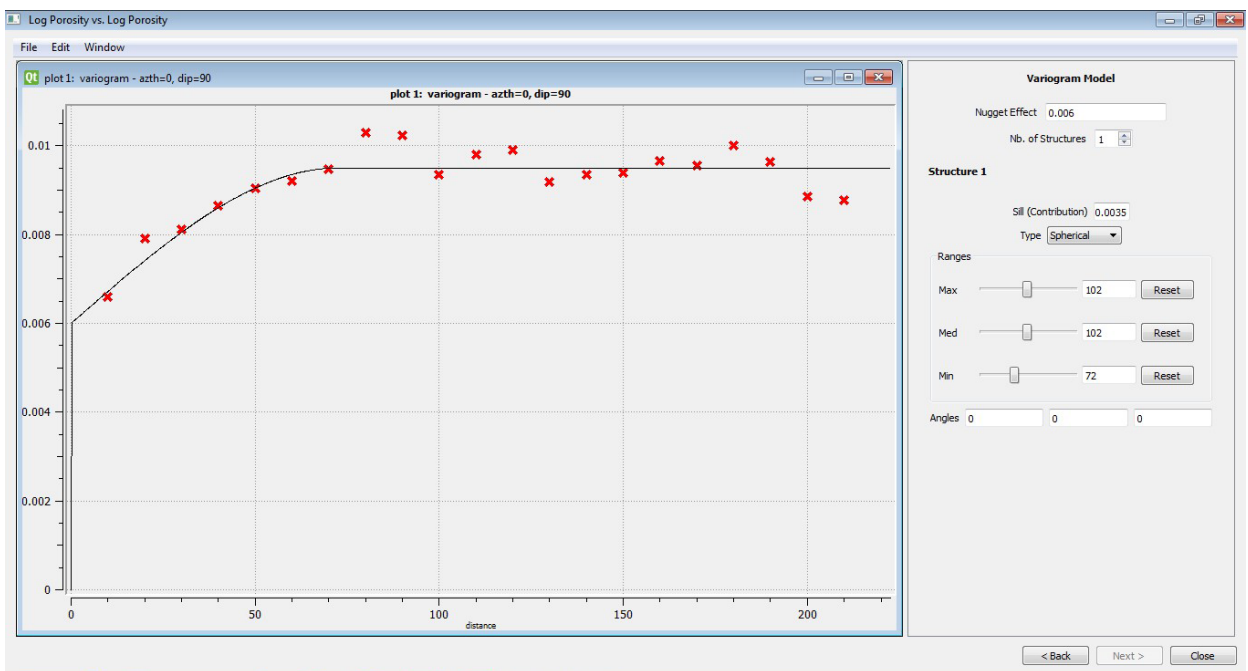

Figure 6c: Vertical experimental and model semivariogram. 
Table 1: Semivariogram parameters.

\begin{tabular}{cccccc} 
Azimuth & Nugget & Sill & Range (m) & $\begin{array}{c}\text { Nugget/Sill } \\
\text { ratio (\%) }\end{array}$ & Model Type \\
\hline $\begin{array}{c}45 \\
\text { (Major Direction) }\end{array}$ & 0.006 & 0.0099 & 6480 & 60.6 & Spherical \\
\hline $\begin{array}{c}135 \\
\text { (Minor Direction) }\end{array}$ & 0.006 & 0.0111 & 1750 & 54.1 & Spherical \\
\hline Vertical & 0.006 & 0.0095 & 72 & 63.2 & Spherical \\
\hline
\end{tabular}

Table 2: Spatial Dependence of Variables [14].

\begin{tabular}{cc} 
Nugget/Sill Ratio (\%) & Inference \\
\hline$<25 \%$ & $\begin{array}{c}\text { Strong Spatial } \\
\text { Dependence }\end{array}$ \\
\hline $25 \%-75 \%$ & $\begin{array}{c}\text { Moderate Spatial } \\
\text { Dependence }\end{array}$ \\
\hline$>75 \%$ & Low Spatial \\
& Dependence \\
\hline
\end{tabular}

equal to the variance of the data, [13]. This suggests that the spatial structure exhibits geometrical anisotropy in porosity distribution as seen in Figure 6a-c.

As observed in Table 2, the nugget/sill ratio of porosity for all the semivariogram models are moderate based on the classification by Wei et al., 2007. This suggests that the porosity in the study area has a moderate spatial dependence and as a result, local variations within the study area might be captured.

\section{Kriging}

The kriging models (Figure 7) show variability in porosity distribution both laterally and vertically which suggests the heterogeneity of underlying features within the study area. It also reveals interbedded horizontal layering of geologic materials. The kriging variance map (Figure 8) shows principally high errors or uncertainty outside the zone of influence. This may be attributed to data quality or lack of data outside zone of influence

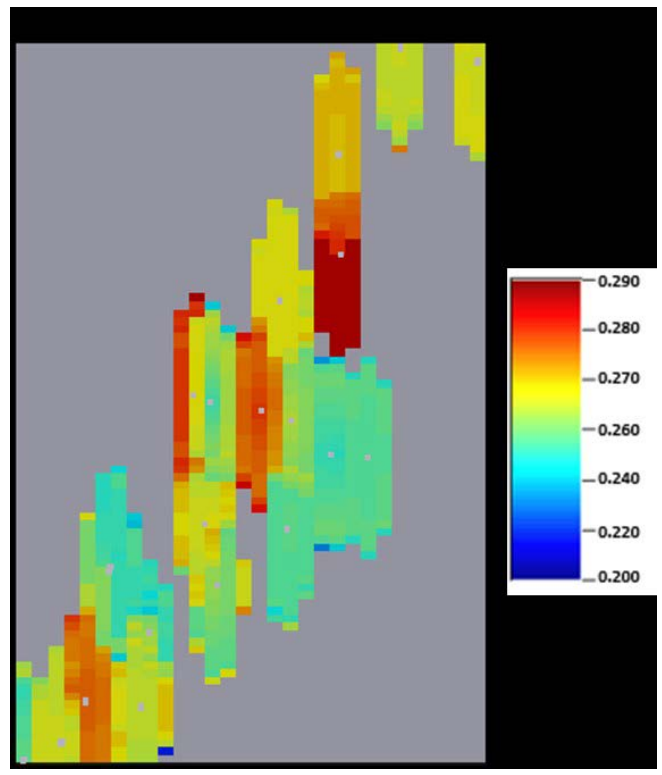

Figure 7: Kriging map.

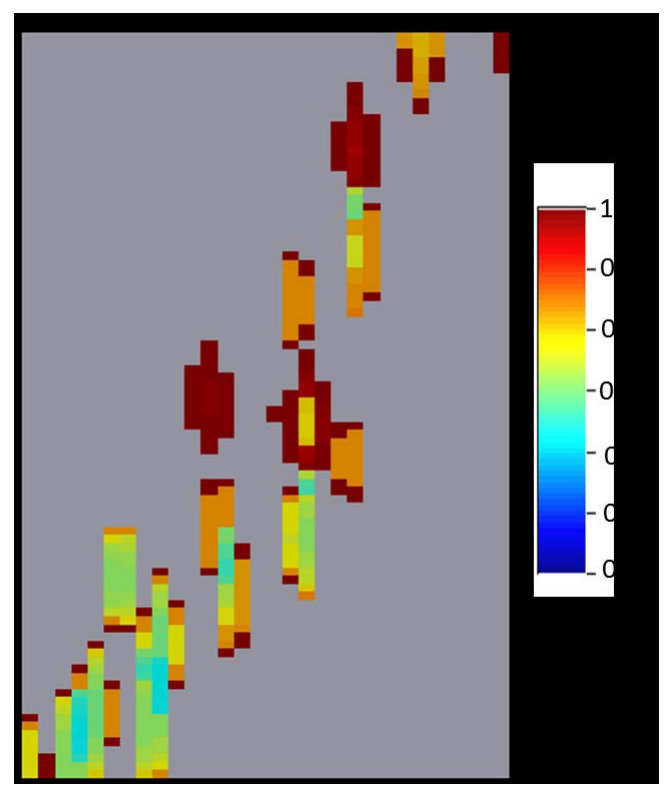

Figure 8: Kriging variance. 

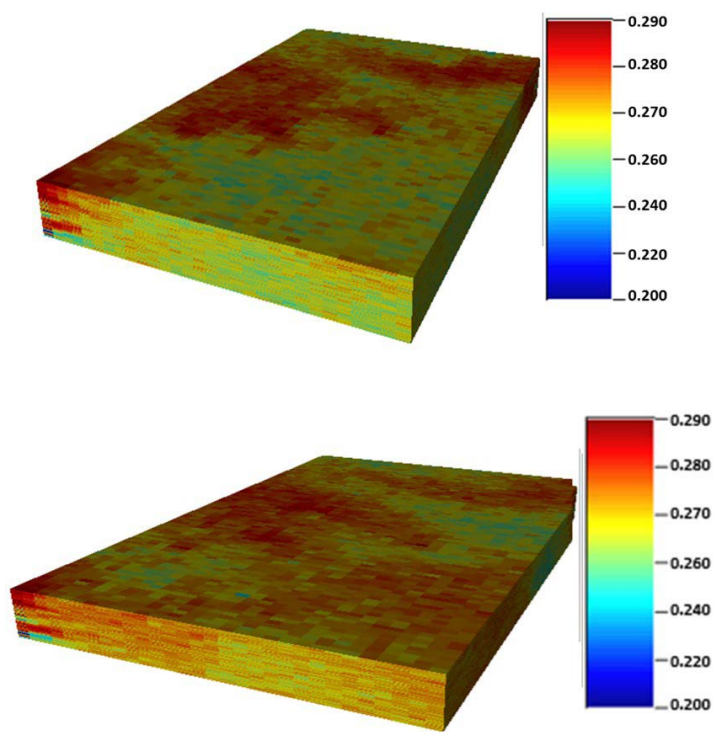

Figure 9: Realizations 1 and 2.

\section{Simulation Realizations}

Figures 9-11 show six realizations generated using conditional SGS algorithm. Visual observation shows that the models are similar in terms of variability. The similarity of statistics of the models (Table 3) suggests that each of the realizations can independently represent the true picture of the subsurface geology within the study area. The outputs are set of probabilistic models, which can serve as a measure of uncertainty in predicting porosity distribution within the study area.

Generally, they all show variability in porosity distribution both laterally and vertically, which suggests the heterogeneity of underlying features within the study area. The statistical summary (Table 3 ) is very similar in all respects. The mean porosity of the six realizations ranges from 0.24 to 0.25 , which is very close to the mean of the real data (0.25). The coefficient of variation of the models ranges from 0.067 to 0.081 , while that of the real data is 0.081 .

$\mathrm{Q}-\mathrm{Q}$ plot (Figure 12a-f) is a confirmatory test for normality of the generated realizations, which clearly shows positive slope, and alignment of the data along a straight line.

Based on the summary statistics and Q-Q plots of the realizations, we ranked the realizations (Table 4). Realization 6 among others appears most true with less uncertainty to represent
Figure 10: Realizations 3 and 4.

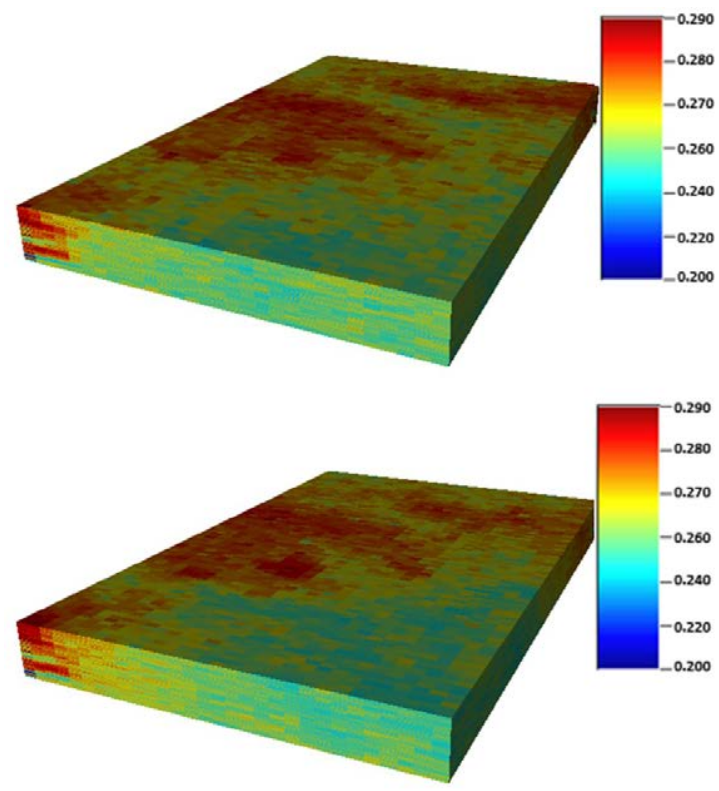

Figure 11: Realizations 5 and 6.

the subsurface geology of the study area. This model could be incorporated in any data analysis of the field in order to effectively improve the prediction of porosity and reduce uncertainty. Also, the porosity model could be used as an initial condition for simulation of flow in the field. 
Table 3: Statistics summary of realizations

\begin{tabular}{cccccccc}
$\begin{array}{c}\text { Realization } \\
\text { No }\end{array}$ & Maximum & Median & Minimum & Mean & $\begin{array}{c}\text { Standard } \\
\text { deviation }\end{array}$ & CV & Variance \\
\hline 1 & 0.28 & 0.24 & 0.22 & 0.25 & 0.041 & 0.0739 & 0.0017 \\
\hline 2 & 0.29 & 0.23 & 0.22 & 0.24 & 0.034 & 0.064 & 0.0012 \\
\hline 3 & 0.28 & 0.24 & 0.22 & 0.25 & 0.038 & 0.068 & 0.0014 \\
\hline 4 & 0.29 & 0.25 & 0.22 & 0.24 & 0.036 & 0.067 & 0.0013 \\
\hline 5 & 0.28 & 0.25 & 0.22 & 0.25 & 0.044 & 0.079 & 0.0019 \\
\hline 6 & 0.28 & 0.25 & 0.22 & 0.25 & 0.045 & 0.081 & 0.002 \\
\hline Real Data & 0.28 & 0.25 & 0.22 & 0.25 & 0.099 & 0.081 & 0.002 \\
\hline
\end{tabular}

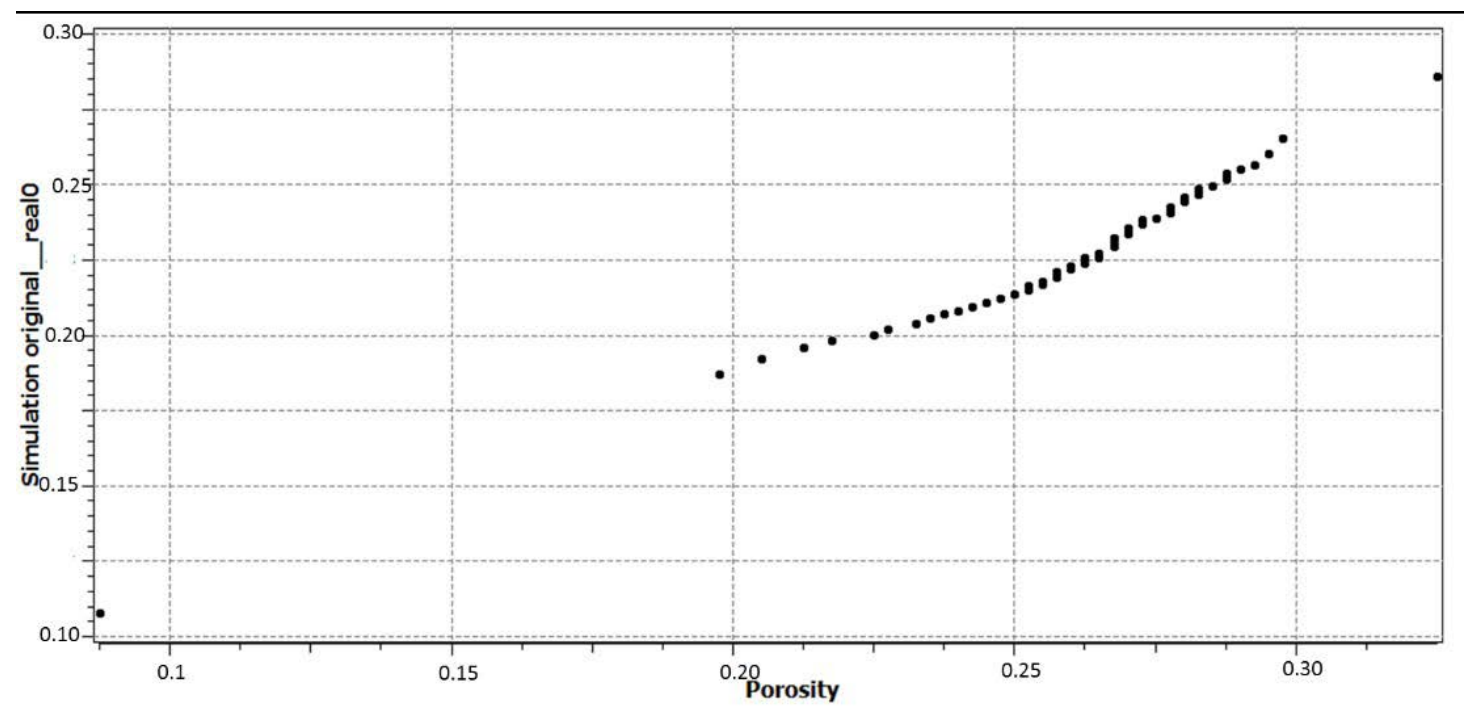

(a)

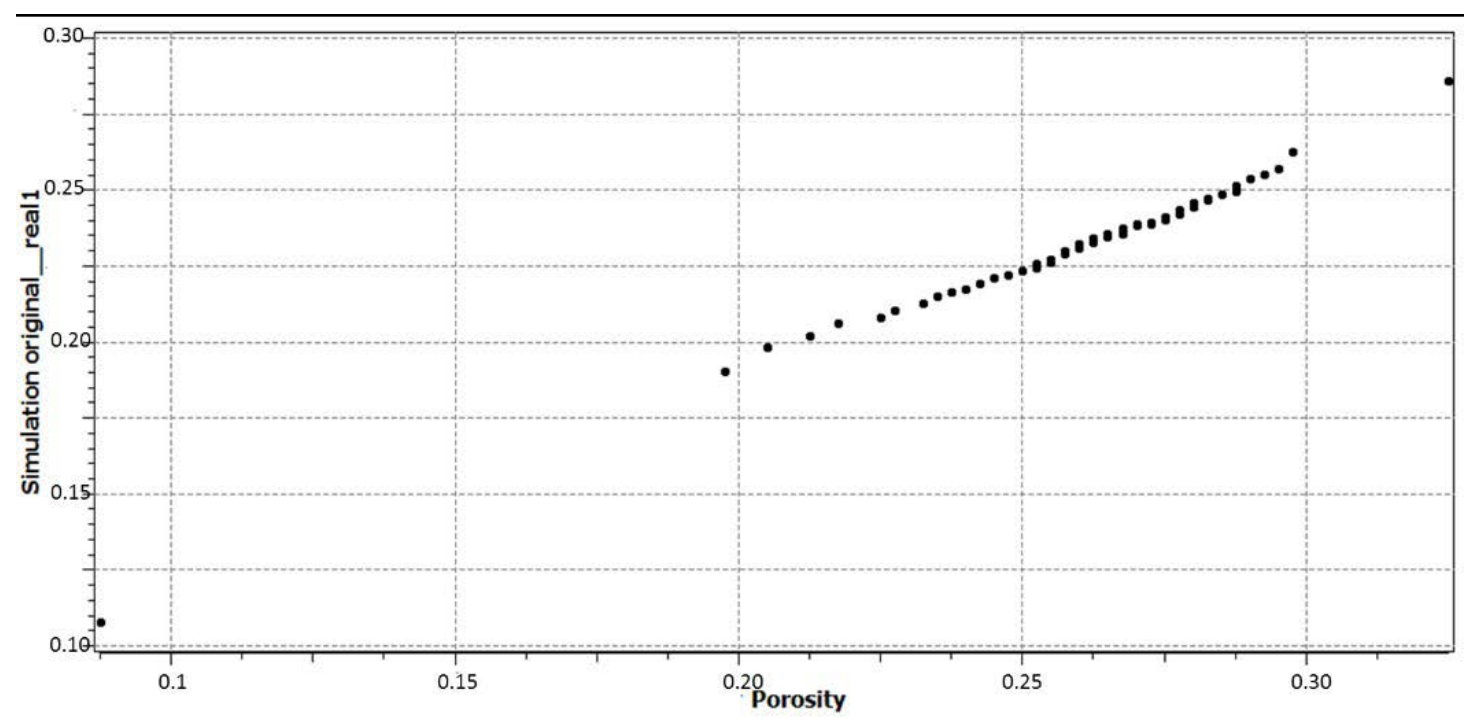

(b)

Figure 12: Q-Q Plot of (a) realization 1 (b) realization 2. 


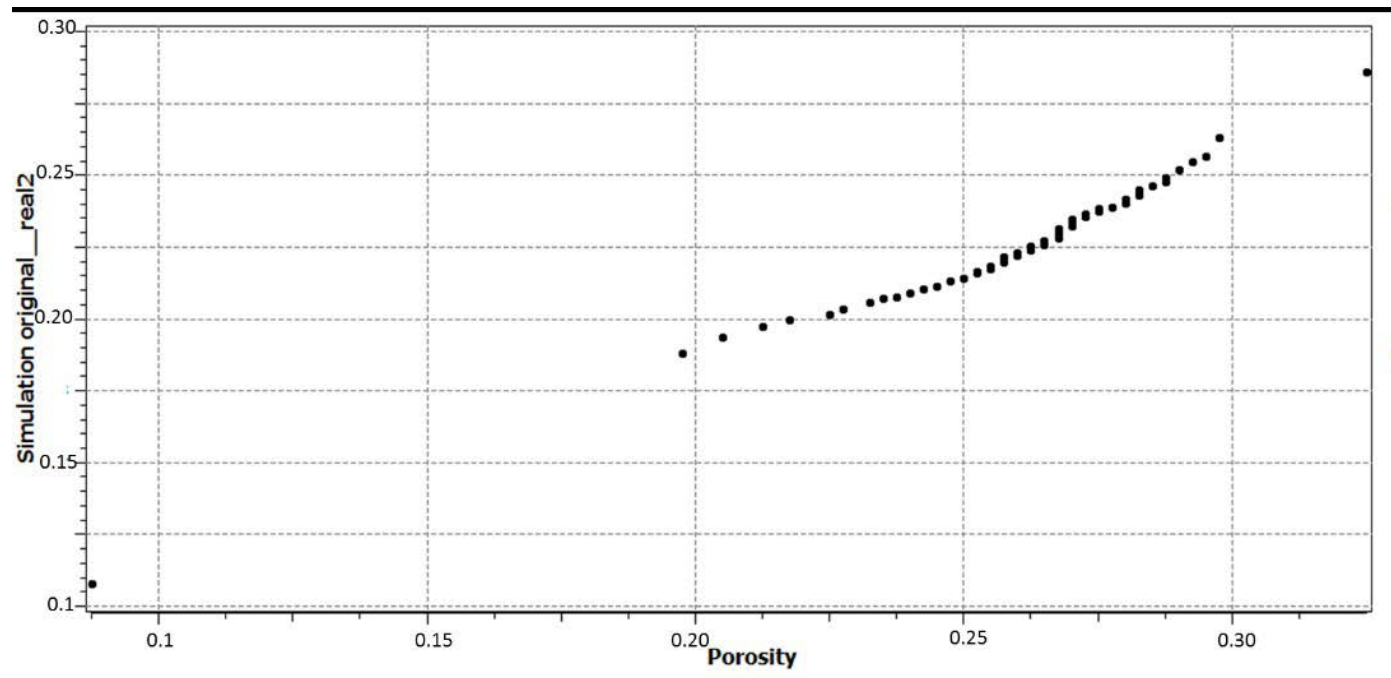

(c)
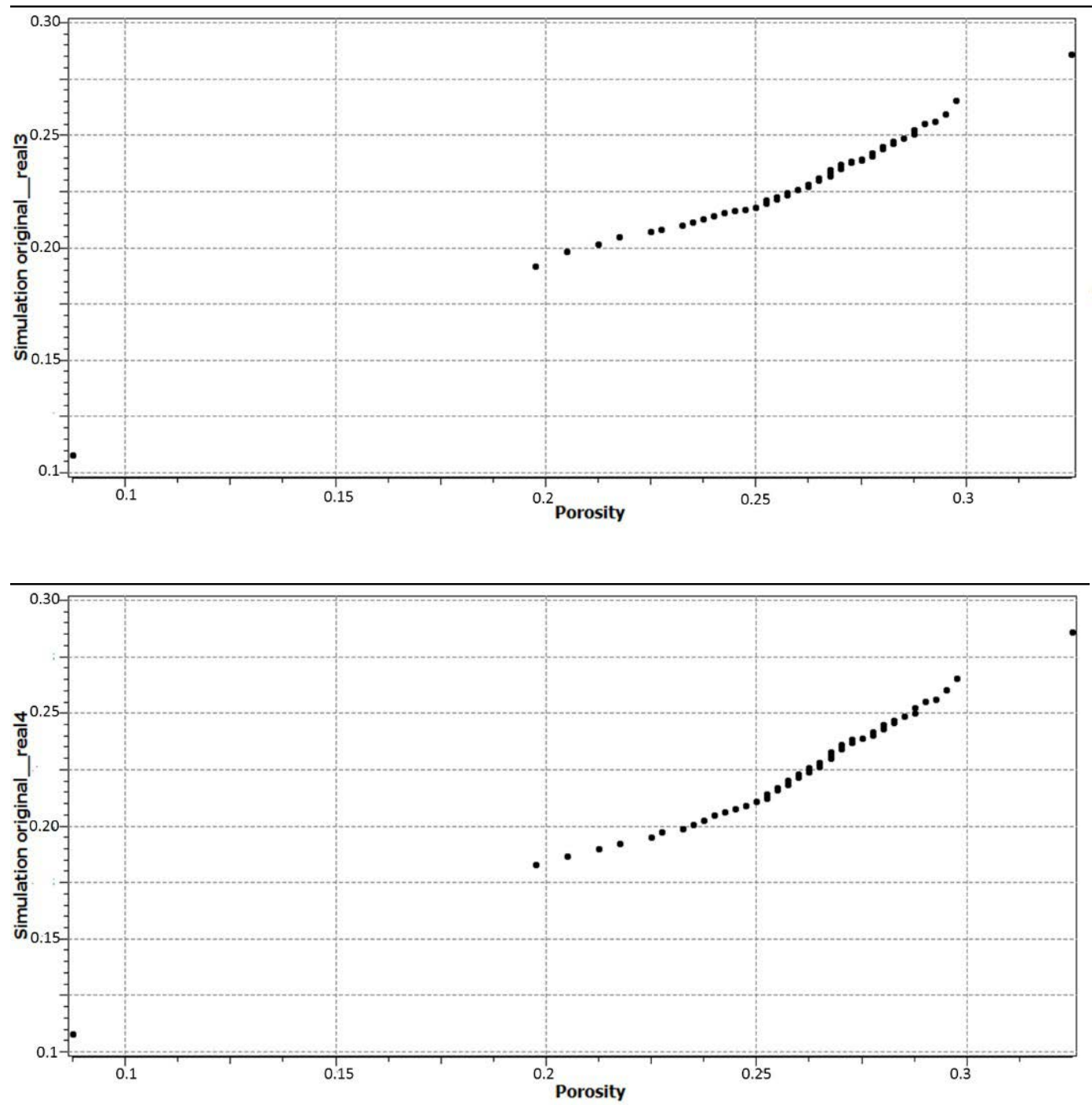

(e)

Figure 12: $Q-Q$ Plot of $(c)$ realization $3(d)$ realization $4(e)$ realization 5. 


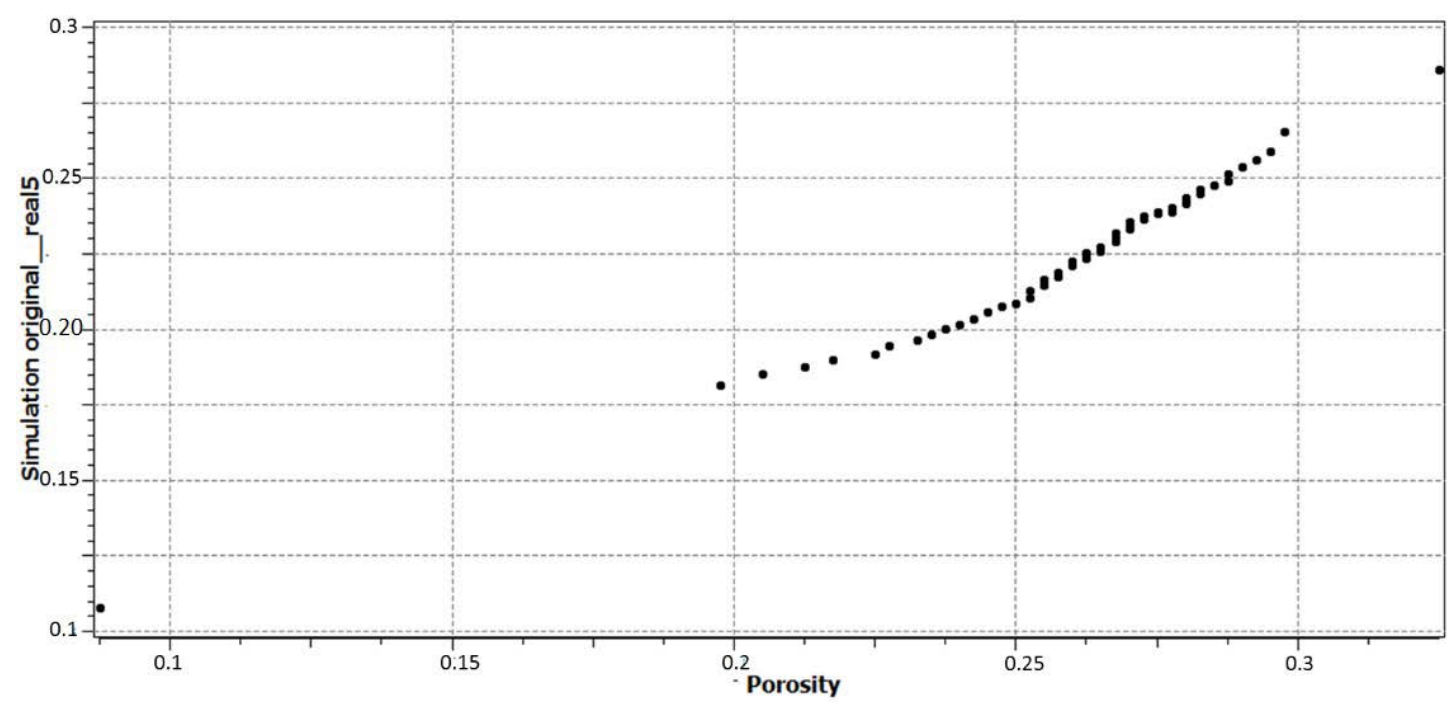

(f)

Figure 12: $Q-Q$ Plot of $(f)$ realization 6.

Table 4: Ranking of porosity models.

\begin{tabular}{cc} 
Rank & Realization No \\
\hline 1 & 6 \\
\hline 2 & 5 \\
\hline 3 & 1 \\
\hline 4 & 3 \\
\hline 5 & 4 \\
\hline 6 & 2
\end{tabular}

\section{Conclusions}

We have used a geostatistical technique to model porosity data in 'OBA' field, onshore Niger Delta. The porosity range in the area is 0.10-0.30 after filtering of outliers, which suggests that the lithology could be sand or shale. The standard deviation for the entire field ranges from $0.04-0.08$, coefficient of variation ranges from $0.15-0.28$. Based on this, linear and parametric geostatistics were employed to process the data in order to build geostatistical model of the subsurface geology. The semivariogram shows the major direction of continuity "azimuth of 45", spherical geometrical anisotropy. Kriging map shows clearly vertical and horizontal heterogeneity of the study area and subsurface interbedded layers, which agrees with the result of the semivariogram. However, kriging variance model indicates high value of error outside the zone of influence which may be due to insufficient number of the well data. Six realizations were generated and the results indicates that any one of the realizations can independently represent the true picture of the subsurface geology within the study area with realization 6 ranked as the best and realization 2 as the lowest. We therefore recommend that geostatistical estimation and simulation to be incorporated in any geologic data analysis and that integration of more than one variable from multiple sources will effectively improve the prediction and reduce the uncertainty.

\section{References}

[1] Ming-Sheng, Y., Yu-Pin, L., Liang-Cheng, C. (2006): Designing an optimal multivariate geostatistical groundwater quality monitoring network using factorial kriging and genetic algorithms. Environ Geol 50, pp.101-121.

[2] Al-Kuisi, M., Al-Qinna, M, Margane, A, Aljazzar, T. (2009): Spatial assessment of salinity and nitrate pollution in Amman Zarqa basin: a case study. Environ Earth Sci 59, pp.117-129.

[3] Sahebjalal, E. (2012): Application of geostatistical analysis for evaluating variation in groundwater characteristics. World Appl Sci J 18(1), pp.135-141. 
[4] Karatas, B.S., Camoglu G., Olgen M. (2013): Spatio-temporal analysis of the depth and salinity of the groundwater using geostatistics integrated with GIS, the Menemen Irrigation System, Western Turkey. Int J Environ (Ekoloji) 22(86), pp.36-47.

[5] Doust, H., Omatsola, M. (1990): Petroleum geology of the Niger delta. Geological Society, London, Special Publications, 50, pp.365-365.

[6] Whiteman, A (1982): Nigeria: its Petroleum Geology, Resources and Potential. Graham and Trotman, London.

[7] Stacher, P. (1995): Present understanding of the Niger delta hydrocarbon habitat: Geology of Deltas. AA Balkema, Rotterdam, pp 257-267

[8] Weber, K.J. (1987): Hydrocarbon distribution pattern in Nigerian growth fault structures controlled by structural style and stratigraphy. J Petrol Sci Eng 1, pp.1-12.

[9] Short, K., Stauble, A. (1967): Outline of geology of Niger delta. AAPG Bull 51, pp.761-779.
[10] Tuttle, M.L., Charpentier, R.R., Brownfield, M.E. (1999): The Niger delta petroleum system: Niger delta province, Nigeria, Cameroon, and Equatorial Guinea, Africa: US Department of the Interior, US Geological Survey

[11] Ekweozor, C.M., Okoye, N.V. (1980): Petroleum source-bed evaluation of Tertiary Niger Delta. AAPG Bull 64, pp.1251-1259.

[12] https://www.minitab.com/uploadedFiles / Documents/getting-started/Minitab 17 . GettingStarted-en.pdf.

[13] Yarus, J.M. and Chambers, R.L. (2006): stochastic modeling and geostatistics: Principles, methods and case studies. AAPG Computer Applications in Geology. 3, pp. 27-36.

[14] Wei, H., Dai, L. and Wang, L. (2007): Spatial distribution and risk assessment of radionuclides in soils around a coal-fired power plants: a case study from the city of Baoji China. Environ Res. 104, pp.201-208. 
